\title{
A Clinically Suitable Approach to Whole-Body Imaging for Quantification of Regional Perfusion: Validation of Positron Emission Tomography (PET) with ${ }^{62} \mathrm{Cu}$-ETS and Image-based Tracer Kinetic Modeling
}

\author{
Monica Cheng ${ }^{1}$, Nathaniel J. Smith ${ }^{1}$, Wendy L. Territo ${ }^{1}$, Carla J. Mathias ${ }^{1}$, James \\ W. Fletcher ${ }^{1}$, Theodore F. Logan ${ }^{2}$, Mark A. Green ${ }^{1}$, Gary D. Hutchins ${ }^{1}$ \\ ${ }^{1}$ Indiana University School of Medicine, Department of Radiology and Imaging \\ Sciences; ${ }^{2}$ Indiana University Simon Cancer Center
}

Background \& Hypothesis: We hypothesize that whole-body PET imaging with ${ }^{62} \mathrm{Cu}-\mathrm{ETS}$ and readily implemented tracer kinetic models, can enable absolute quantification of regional perfusion $(\mathrm{mL} \cdot \mathrm{min}-1 \cdot \mathrm{g}-1)$ in a fashion that is reproducible; readily standardized across institutions; and logistically suitable for clinical implementation.

Experimental Design: Thirty-five paired ${ }^{62} \mathrm{Cu}-\mathrm{ETS}$ and $\mathrm{H}_{2}{ }^{15} \mathrm{O}$ studies were performed in six Göttingen minipigs to validate the use of image-derived input functions. $\mathrm{H}_{2}{ }^{15} \mathrm{O}$ estimates of tissue perfusion served as a reference standard for comparison with ${ }^{62} \mathrm{Cu}$-ETS. To demonstrate quantitative whole-body perfusion imaging in humans, paired ${ }^{62} \mathrm{Cu}-\mathrm{ETS}$ and $\mathrm{H}_{2}{ }^{15} \mathrm{O}$ studies were performed in 14 renal cell carcinoma patients both prior to and following sunitinib therapy.

Results: The pig studies showed a strong correlation between regional blood flow estimates made with ${ }^{62} \mathrm{Cu}$-ETS and $\mathrm{H}_{2}{ }^{15} \mathrm{O}$, using image-derived input functions with tracer kinetic model-based corrections for ${ }^{62} \mathrm{Cu}$-ETS decomposition in blood (slope $=0.932, R^{2}=0.746$ ). High quality voxel-wise ${ }^{62} \mathrm{Cu}$-ETS perfusion and blood volume parametric images demonstrated a strong correlation with $\mathrm{H}_{2}{ }^{15} \mathrm{O}$ across all tissues within the imaging field-of-view. Using a same-day testretest design, which was then repeated across two weeks, the animal study demonstrated good test-retest variability (TRV) for ${ }^{62} \mathrm{Cu}-\mathrm{ETS}$ and $\mathrm{H}_{2}{ }^{15} \mathrm{O}$ with TRV of $6.3 \% \pm 5.40 \%$ and $5.0 \% \pm 4.77 \%$, respectively. These findings strongly support application of the modeling methods to the human data, which is currently in progress.

Conclusion \& Potential Impact: Whole-body imaging to non-invasively quantify regional perfusion holds promising potential for clinical implementation, using ${ }^{62} \mathrm{Cu}$-ETS PET coupled with tracer kinetic models that rely solely on the acquired imaging data. 